\title{
Analysis of the Possibilities of Improving Environmental Conditions in Lecture Halls Using Mechanical Ventilation
}

\author{
Andrzej Grzebielec ${ }^{1 *}$, Adam Szelągowski ${ }^{2}$, Krzysztof Bruzi $^{3}$ \\ ${ }^{1,2}$ Institute of Heat Engineering, Faculty of Power and Aeronautical Engineering, \\ Warsaw University of Technology, Warsaw, Poland \\ ${ }^{3}$ Stropex Sp. J., Poland
}

Received 28 February 2020; accepted 24 March 2020

\begin{abstract}
Didactic classes are conducted in lecture halls usually adapted from the technical side to present content. Audiovisual and sound systems are installed. Unfortunately, in many cases, classrooms are designed from the point of view of air conditioning and ventilation, just like office rooms. As a result, during classes, even in rooms where air conditioning occurs, the conditions change so unfavourably that both teacher and students experience discomfort. The work analyzes the change in temperature, $\mathrm{CO}_{2}$ concentration, PM2.5 concentration and relative humidity in the room, where heat gains from people and equipment as well as moisture gains exceed design values. The work uses a channel-free Respireco recuperator with cyclic operation. First, the thermodynamic properties of the recuperator itself were checked, and then it was tested in a selected Polish primary school. The results show that this type of recuperators are able to provide correct indoor climatic conditions in lecture halls. The use of mechanical ventilation using a recuperator with a ceramic heat recovery caused the $\mathrm{CO}_{2}$ concentration in the room to drop by $50 \%$ during classes. However, PM2.5 concentration was maintained at a level three times lower than in a room without mechanical ventilation. It should therefore be concluded that the use of mechanical ventilation with recuperation not only reduces heating costs but also significantly improves air quality.
\end{abstract}

Keywords: ventilation, mechanical ventilation with ceramic heat recovery, environmental changes, dustiness, $\mathrm{CO} 2$ concentration, comfort.

\section{Introduction}

Air pollution in Poland is at a very high level (Domańska \& Wojtylak, 2014; Namieśnik et al., 1992). The main source of pollution are boilers in single-family houses, in which very poor quality fuels are burned. Figure 1 shows the results of PM2.5 measurement in the center of Warsaw on January 17, 2020. Despite the fact that Warsaw has the largest district heating system in the European Union (Grzebielec \& Rusowicz, 2013; Grzebielec et al., 2015; Werner, 2017; Lund et al., 2010), pollution from single-family housing estates also causes pollution in the city center, where the connection of buildings to the heating network dominates (Rusowicz et al., 2017).

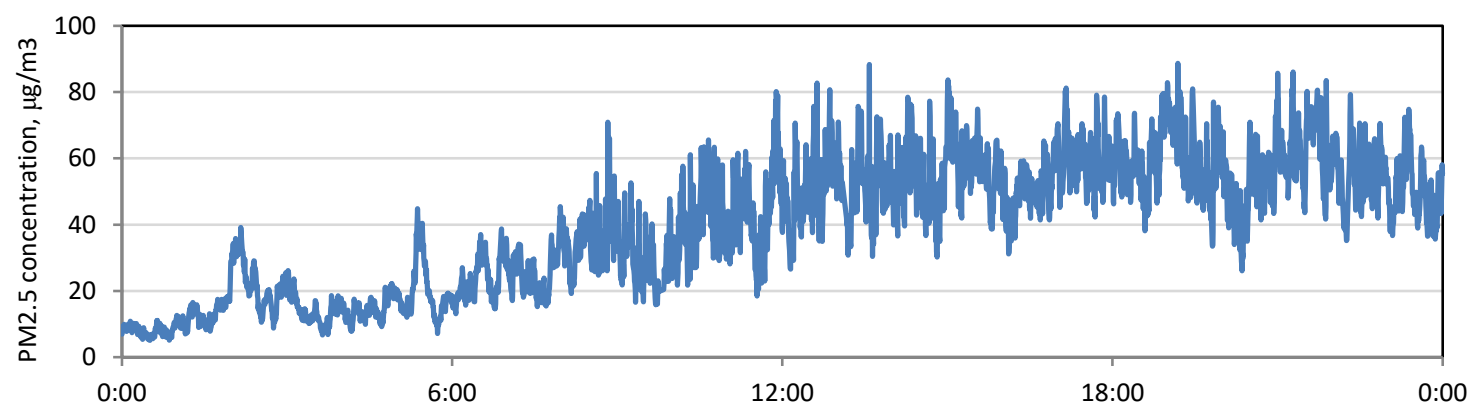

Figure 1. PM2.5 concentration in the center of Warsaw on January 17, 2020

\footnotetext{
${ }^{*}$ Corresponding author. E-mail: andrzej.grzebielec@itc.pw.edu.pl
} 
In Poland, thermo-modernization programs are very well developed, aimed at reducing energy consumption, and thus reducing air pollution. Unfortunately, not everything has been achieved yet (Owczarek \& Baryłka, 2019; Rusowicz \& Ruciński, 2011; Kajurek et al., 2019). While the quality of outdoor air in the current legal system in Poland is difficult to improve, it becomes very important to maintain good indoor air quality. This applies above all to rooms where children are present (Bernstein et al., 2004; Liu et al., 2015; Pui et al., 2014; Griffiths \& Eftekhari, 2008; Rosbach et al., 2013).

Mechanical ventilation used in buildings is usually equipped with filters of various classes. Air filtration is designed to protect such device components as heat exchangers, recuperators or fans against pollution, but at the same time is designed to improve the quality of air in buildings (Xuehuan et al., 2019). The issues of air filtration are explored by many researchers and all indicate that due to appropriate filtration it is possible to achieve satisfactory air quality, even when the outside air is heavily polluted (Xuehuan et al., 2019; Park et al., 2011). Studies show that, for example, PM2.5 air pollution inside rooms can be even several times smaller than outside.

As part of this study, it was decided to investigate the impact of using a periodic recuperator on classroom air quality. In the first part, the thermal efficiency of the recuperator was determined in laboratory conditions, and then the air condition was monitored during its operation at the classroom. The novelty of this research is the fact that the research used a recuperator with periodic operation/flow rather than a solution based on a cross or rotary recuperator as in most cases.

\section{Methodology}

\subsection{Analysed equipment}

To analyze the impact of recuperation on air quality, a Stropex Respireco ventilation device was used for energy efficiency testing. From a technical point of view, this device is a local, single-fan heat recovery unit (Jaworski, 2019; Wasilczuk, 2019; Adamski, 2008; Grzebielec et al., 2014).

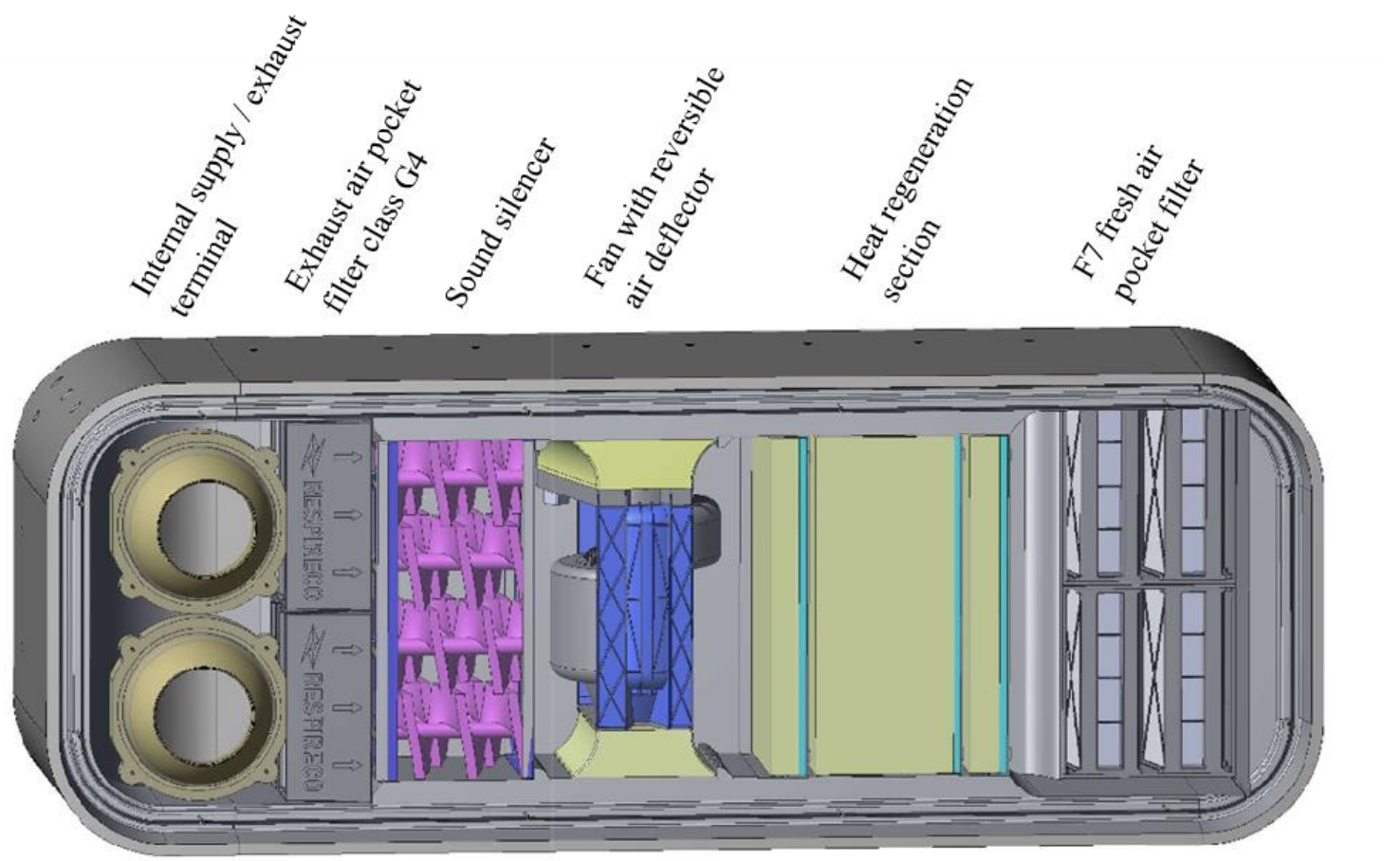

Figure 2. Photo of the interior of the Respireco device

The principled scheme of the device is presented in Figure 2 shows a schema of the device used in the experiment.

\subsection{Ventilation device work parameters}

The tested ventilation device works periodically. In the first stage of work, it supplies fresh, filtered air to the room; in the second stage, it expels used air from the room to the outside. By using a heat-accumulating ceramic material, heat is recovered from the used air. The regenerator can work in one of 10 gears (fan speed) and with any set switching time between the supply and exhaust stages. 


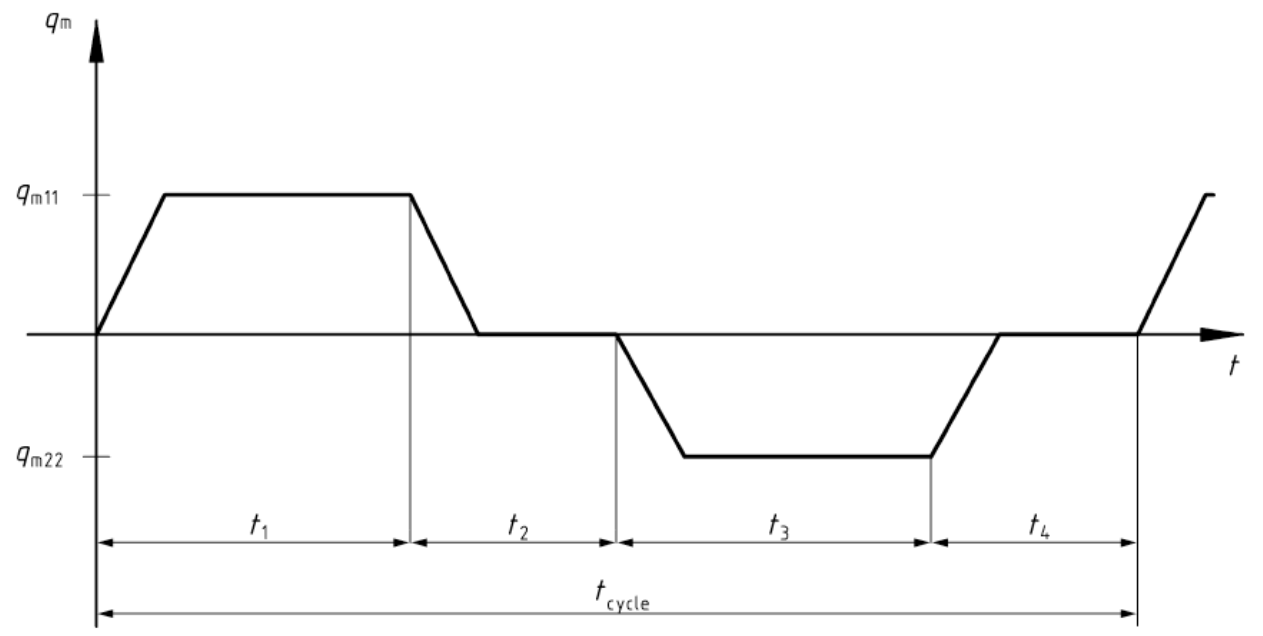

Figure 3. Mass air rate row for tested device (EN 13141-8:2014-09 Ventilation for Buildings - Performance Testing of Components/Products for Residential Ventilation - Part 8: Performance Testing of Un-Ducted Mechanical Supply and Exhaust Ventilation Units (Including Heat Recovery) for Mechanical Ve, n.d.)

The thermal efficiency of the regenerative heat exchanger was tested before mounting the device in the classroom according to standard PN-EN 13141-8: 2014-09. Operation phases of the tested device are presented in Figure 3. The value of thermal efficiency is calculated according to:

$$
\eta_{\theta, s u}=\frac{\theta_{22}-\theta_{21}}{\theta_{11}-\theta_{21}} \cdot \frac{q_{m 22}}{q_{m 11}}
$$

where: $\theta_{22}$ is supply air temperature; $\theta_{21}$ is outdoor air temperature; $\theta_{11}$ is extract air temperature; $q_{m 22}-$ is mass supply air row rate for steady state; $q_{m 11}$ - is mass extract air row rate for steady state.

\section{Results}

Table 1 presents the results of measurements for a device operating with a switching time between supply and exhaust of 60 seconds. However, Figure 4 presents the average values of the air volume flow in the mode of supply and exhaust for all 10 gears. The air flow varies from around $20 \mathrm{~m}^{3} / \mathrm{h}$ (for the slowest run) to around $85 \mathrm{~m}^{3} / \mathrm{h}$ for the fastest run.

Table 1. Average values of the air stream flowing through the device

\begin{tabular}{|c|c|c|c|c|c|}
\hline \multirow{2}{*}{$\begin{array}{c}\text { Gear (fan } \\
\text { speed) } \\
{[-]}\end{array}$} & \multicolumn{2}{|c|}{ Volumetric flow } & \multicolumn{2}{c|}{ Mass flow } & Nominal mass flow ${ }^{*}$ \\
\cline { 2 - 5 } & inlet & outlet & inlet & outlet & $\mathrm{q}_{\mathrm{m}}$ \\
\hline 1 & $\mathrm{~m}^{3} / \mathrm{h}$ & $\mathrm{m}^{3} / \mathrm{h}$ & $\mathrm{kg} / \mathrm{h}$ & $\mathrm{kg} / \mathrm{h}$ & $\mathrm{kg} / \mathrm{h}$ \\
\hline 2 & 19.53 & 20.21 & 23.44 & 24.25 & 22.66 \\
\hline 3 & 26.16 & 27.53 & 31.39 & 33.04 & 30.34 \\
\hline 4 & 33.41 & 34.66 & 40.09 & 41.59 & 38.75 \\
\hline 5 & 41.32 & 42.17 & 49.59 & 50.61 & 47.94 \\
\hline 6 & 48.48 & 49.09 & 58.18 & 58.91 & 56.24 \\
\hline 7 & 54.49 & 54.88 & 65.39 & 65.86 & 63.21 \\
\hline 8 & 62.12 & 62.26 & 74.55 & 74.71 & 72.06 \\
\hline 9 & 70.01 & 70.76 & 84.02 & 84.91 & 81.22 \\
\hline 10 & 77.11 & 76.66 & 92.53 & 91.99 & 88.92 \\
\hline
\end{tabular}

\footnotetext{
${ }^{*)}$ according to: EN 13141-09.
} 


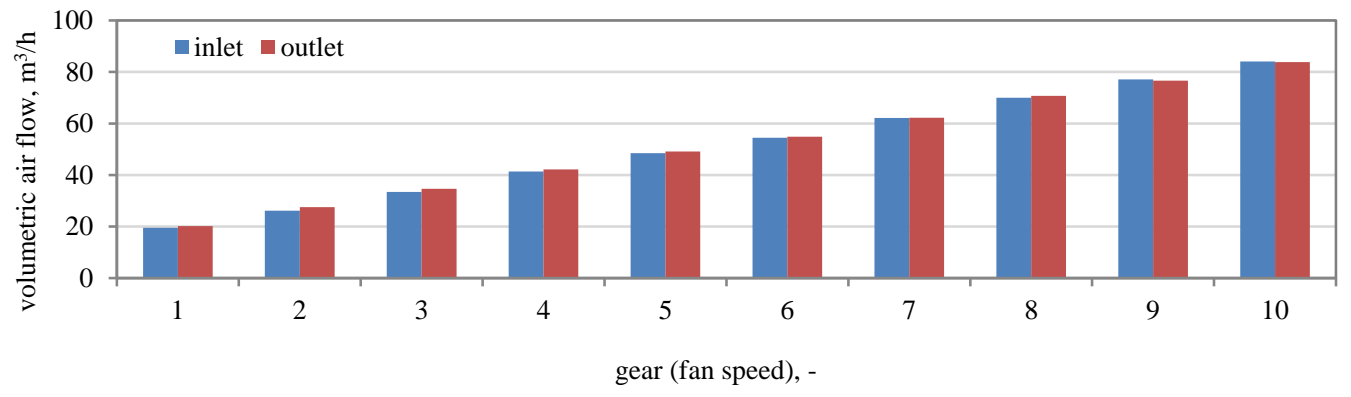

Figure 4. Measured volumetric air flow

Table 2. Electric power of tested device during the operation

\begin{tabular}{|c|c|c|c|}
\hline \multirow{2}{*}{$\begin{array}{c}\text { Gear }(f a n \\
\text { speed) }[-]\end{array}$} & Inlet & Outlet & Direction change (4s) \\
\hline 1 & {$[\mathrm{~W}]$} & {$[\mathrm{W}]$} & 7.59 \\
\hline 2 & 8.35 & 8.31 & 7.60 \\
\hline 3 & 8.65 & 8.62 & 8.61 \\
\hline 4 & 9.21 & 9.17 & 9.00 \\
\hline 5 & 10.05 & 9.98 & 10.11 \\
\hline 6 & 11.14 & 11.11 & 11.25 \\
\hline 7 & 12.25 & 12.25 & 13.30 \\
\hline 8 & 14.02 & 14.03 & 15.50 \\
\hline 9 & 16.13 & 16.13 & 17.97 \\
\hline 10 & 18.67 & 18.64 & 20.90 \\
\hline
\end{tabular}

The device uses EC centrifugal module fan - RadiCal, Type: K3G133-RA01-03(KG 2012). Actual energy consumption by the fan in stable operation mode and during switching between supply and exhaust air is presented in Table 2.

\subsection{Energy efficiency of the tested device}

Figure 5 presents the values of the thermal efficiency coefficient (measured in accordance with PN-EN 13141-8: 2014-09 for Respireco device for all gears (fan speed) for outside air temperature $+7{ }^{\circ} \mathrm{C},+2{ }^{\circ} \mathrm{C},-7^{\circ} \mathrm{C},-15^{\circ} \mathrm{C}$.

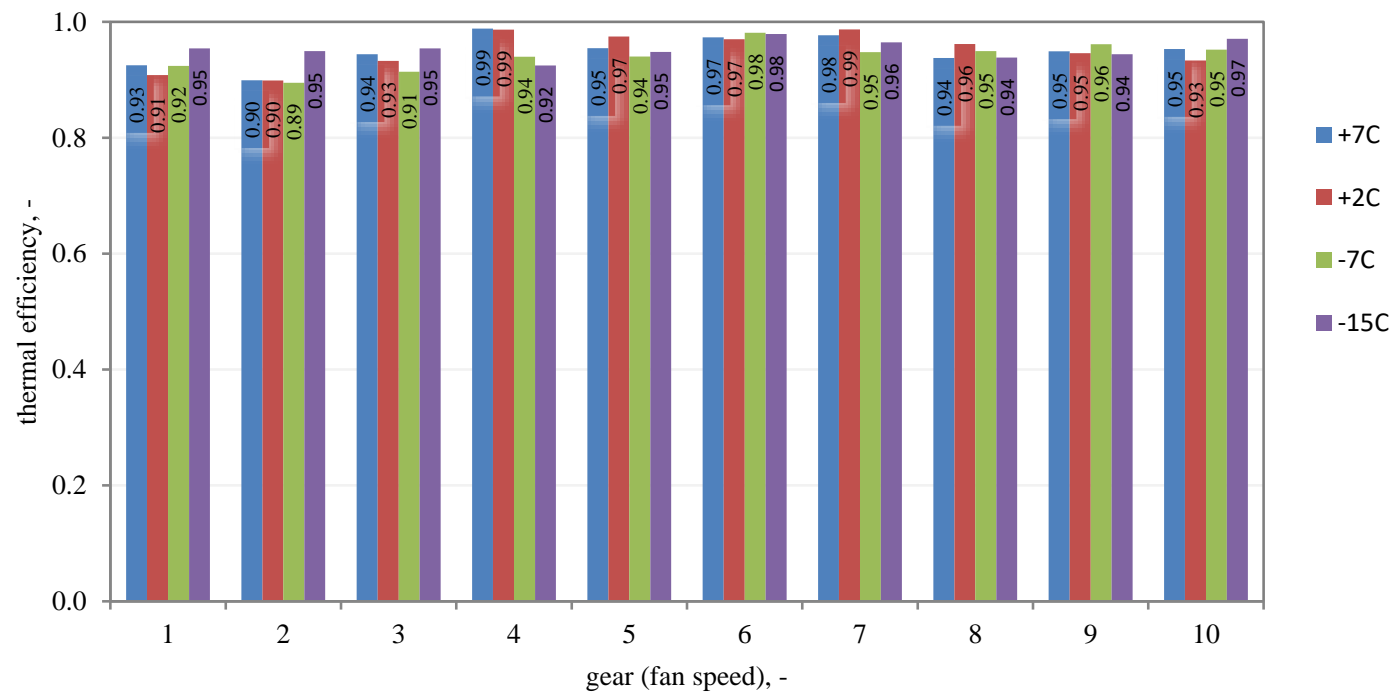

Figure 5. Thermal efficiency of the tested regenerator for different outside air temperature 
Measurements have shown that the device has very high thermal efficiency. The values obtained ranged from 89 to $99 \%$. Studies have also shown that recuperators of this type do not require the use of frost protection, as the temperature of the exchanger structure does not drop below $0{ }^{\circ} \mathrm{C}$.

\subsection{Measurement results at the recuperator installation site}

After testing the device in the laboratory, the device was installed in an elementary school located in Pleszewo (western Poland). Two school rooms with the same cubature and the same spatial orientation in relation to geographical directions were selected for tests, with a similar daily workload and number of students. In one room, environmental parameters were measured for the case of ventilation supported by the mounted device, in the other room ventilation remained unchanged that is, natural ventilation was used. Figure 6 compares the concentration of PM2.5 dust outside and inside the room where the tested recuperator was not used. However, Figure 7 shows the results of $\mathrm{CO}_{2}$ concentration tests for the same situation.

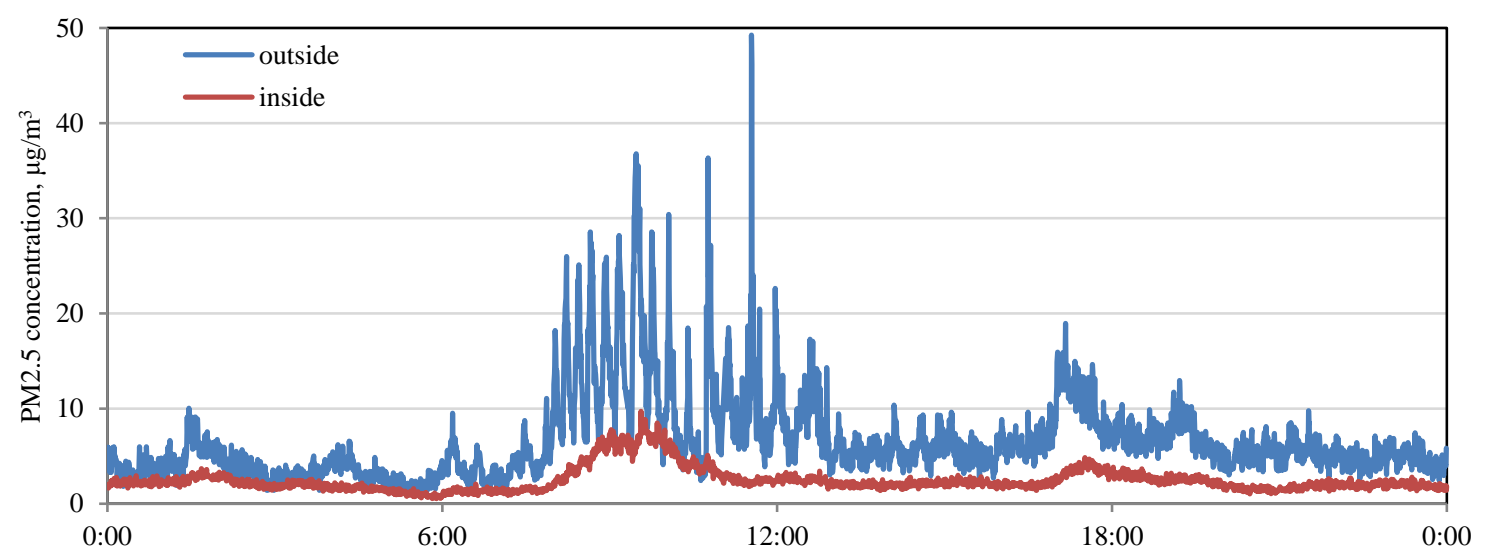

Figure 6. PM2.5 concentration at 2020-02-11 for a classroom without recuperation

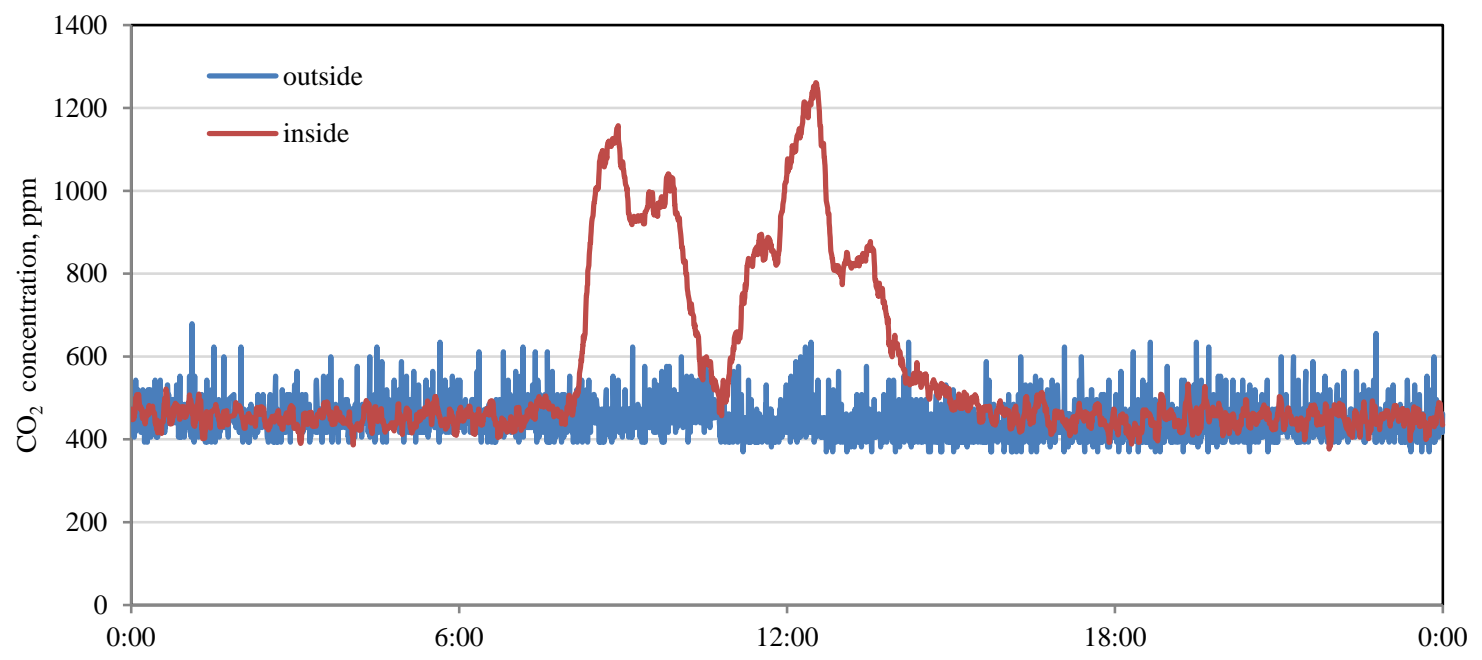

Figure 7. $\mathrm{CO}_{2}$ concentration for a classroom without recuperation

Figures 8 and 9 present the same results at the same time for the rooms where the tested recuperator was used. Comparing the graphs, it can be seen that the use of recuperation significantly reduces $\mathrm{CO}_{2}$ and $\mathrm{PM}_{2.5}$ concentration. The graphs also show that in the case of PM2.5 the concentration of pollution even without the use of recuperation is significantly better on indoor side. 


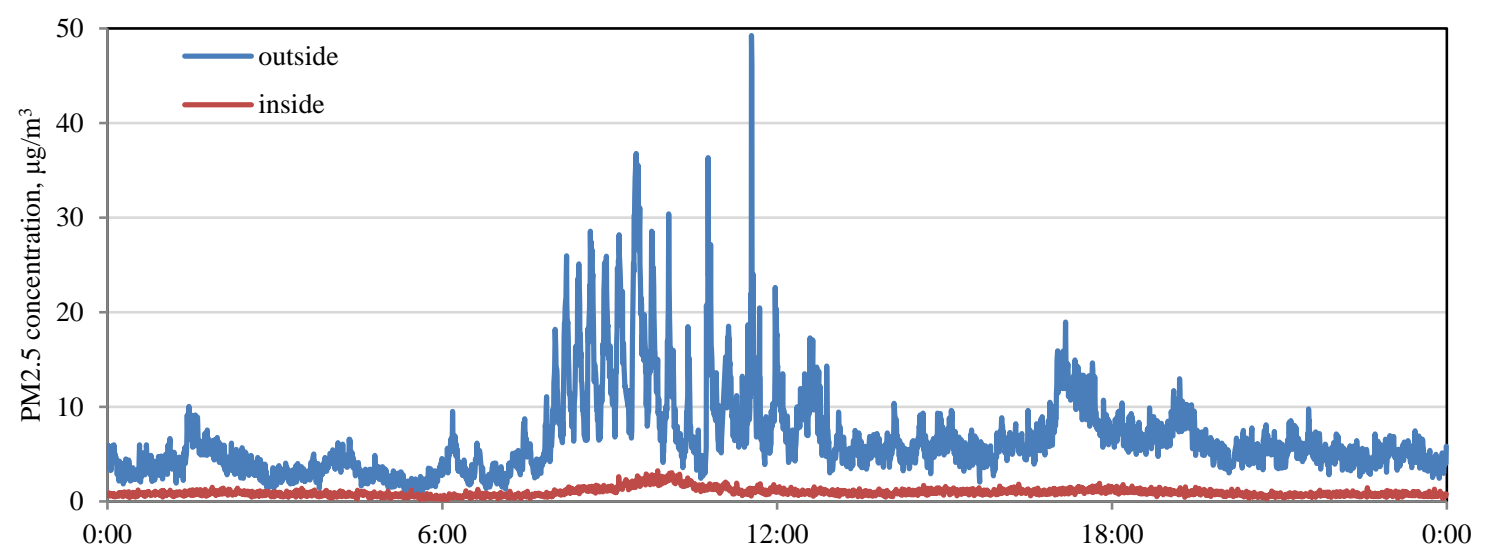

Figure 8. PM2.5 concentration at 2020-02-11 - for a classroom with recuperation

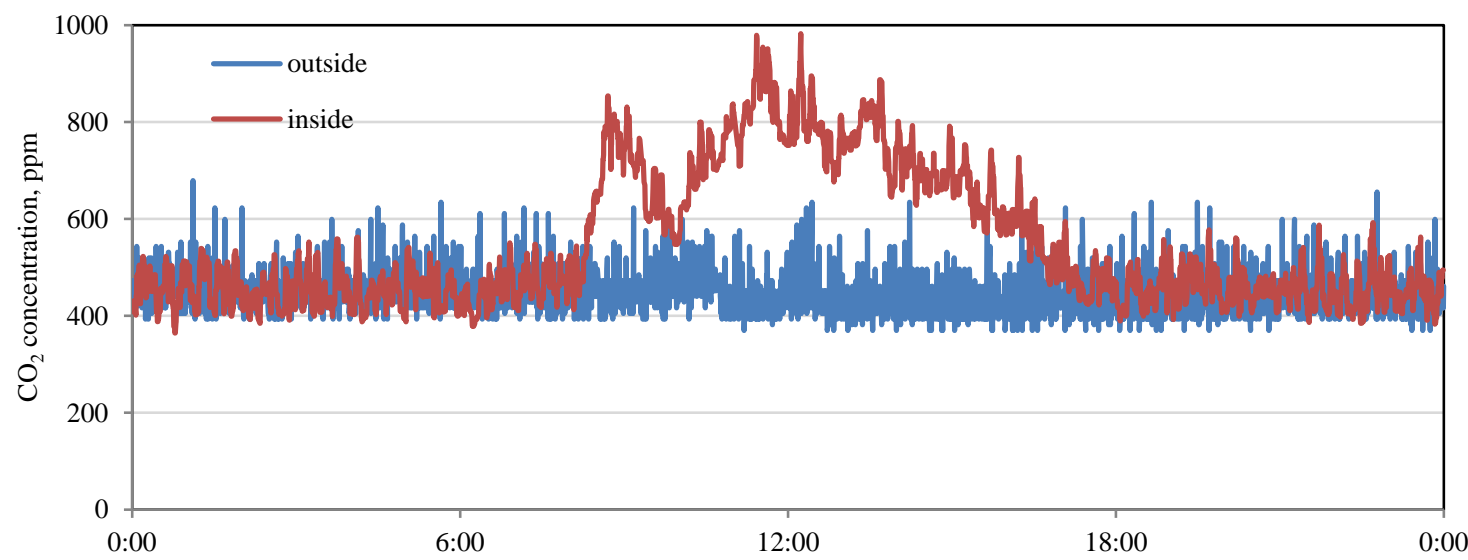

Figure 9. $\mathrm{CO}_{2}$ concentration for a classroom with recuperation at 2020-02-11

Since the conditions in the classrooms were comparable (the temperature was maintained at $20{ }^{\circ} \mathrm{C}$, classes with a similar number of students were performed in parallel), it can be also compared the basic parameters in the classes. Diagrams 10, 11 and 12 present a comparison of PM2.5 concentration, $\mathrm{CO}_{2}$ concentration and relative humidity for the same period.

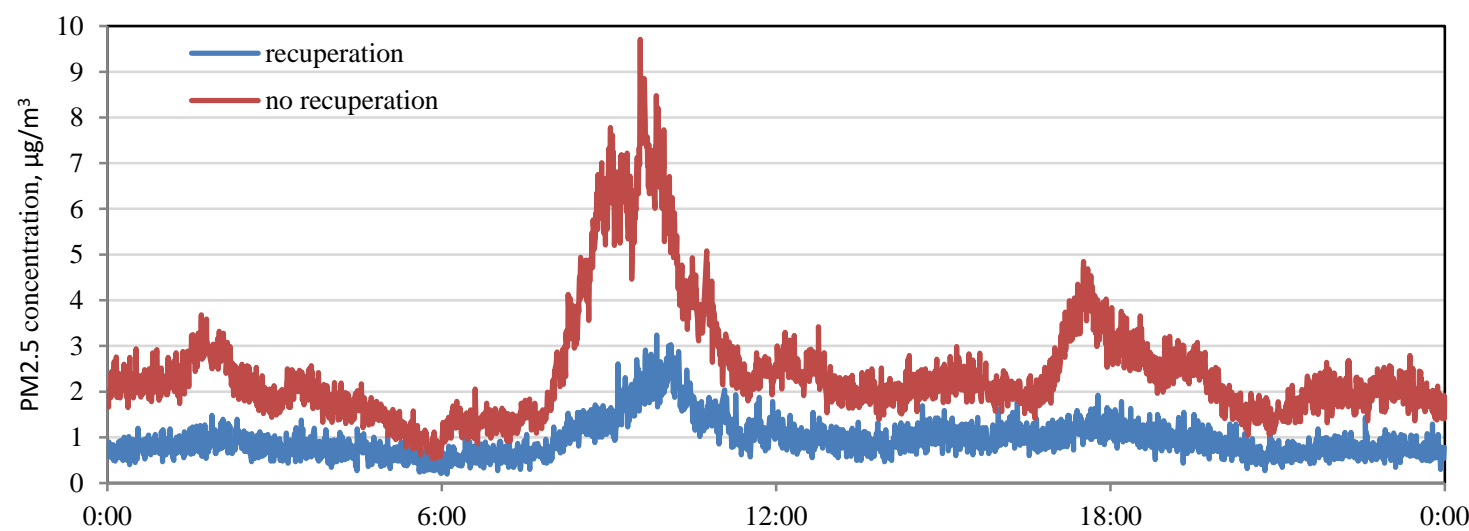

Figure 10. PM2.5 concentration for two classrooms at 2020-02-11 


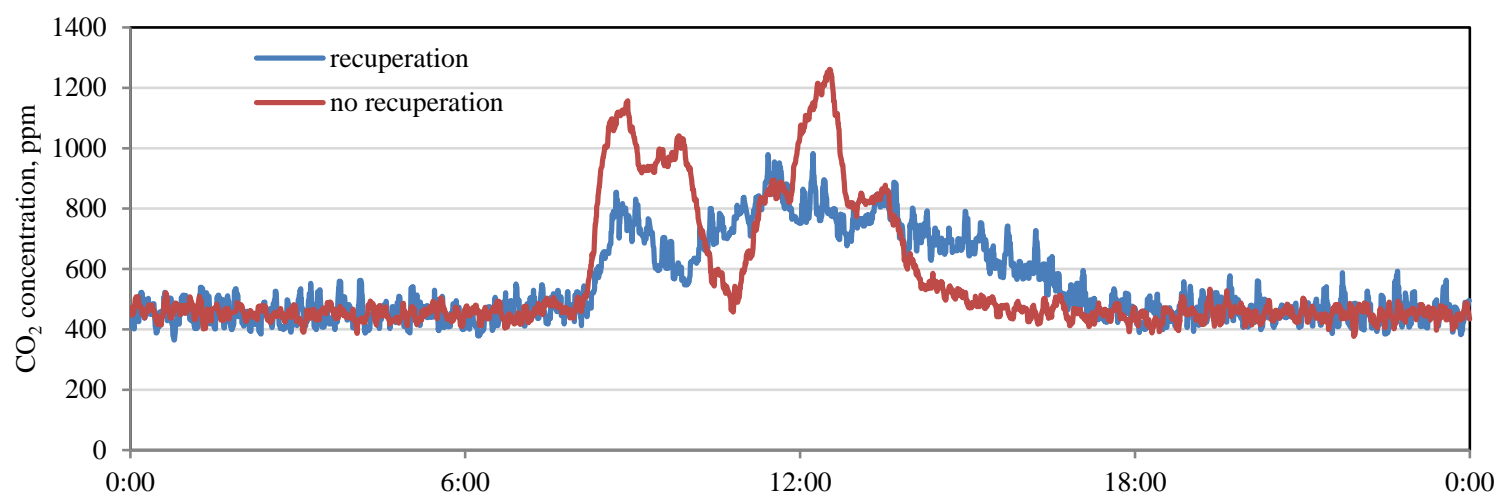

Figure 11. $\mathrm{CO}_{2}$ concentration for two classrooms at 2020-02-11

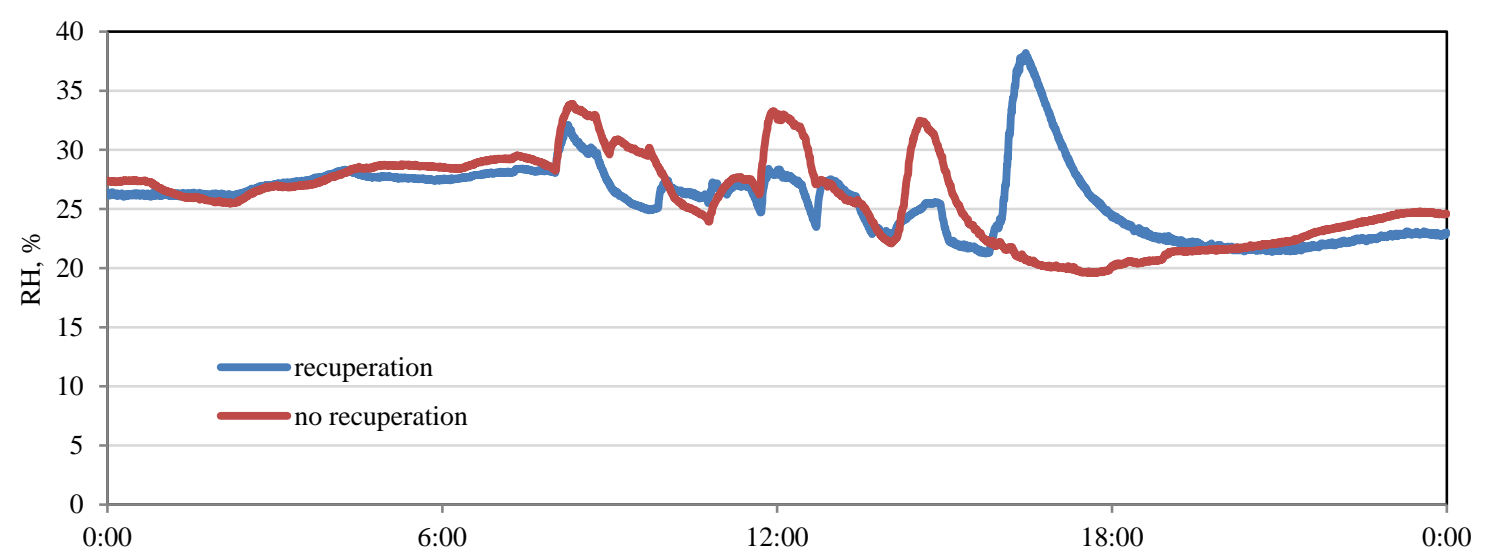

Figure 12. Relative Humidity for two classrooms at 2020-02-11

As shown in the graphs, CO2, PM2.5 concentration and relative humidity were kept at a lower level in a recuperated room.

\section{Conclusions}

The use of a recuperator has definitely improved the air quality in the lecture hall. While in the case of PM2.5 dust it has been noticed that both when using or not using a recuperator, the concentration of dust is definitely lower than outside. Moreover, in both cases there are humiliation of normative requirements which means that in both cases air quality is good. It is also clearly visible that in the room where the recuperator was used, the concentration of PM2.5 is more than 50\% lower. In the case of carbon dioxide, it is very clear that the use of a recuperator definitely has a positive effect on the air quality in the room. Higher $\mathrm{CO} 2$ levels make students and teachers sleepy and absorb knowledge less. Based on the experiments, it can not be clearly stated that the examined recuperator has a positive effect on air quality in humidity point of view. Generally, in northern countries, indoor air is very dry during the winter, because when the outside air temperature is around $0{ }^{\circ} \mathrm{C}$, the absolute humidity level is very low and raising the air temperature causes the relative humidity to drop significantly. Even if there are a large number of students in the room, the humidity does not exceed the recommended values on the contrary the air still seems dry. In this case, the analysis of the impact of recuperation on humidity should be carried out in the summer, when the situation is exactly the opposite.

\section{Acknowledgement}

The work was carried out as part of the research project "Technical Opinion on the Respireco ventilation device" implemented for Stropex Sp. j. 


\section{References}

Adamski, M. (2008). Longitudinal flow spiral recuperators in building ventilation systems. Energy and Buildings. 40(10), 18831888. https://doi.org/10.1016/j.enbuild.2008.04.0088

Bernstein, J. A., Alexis, N., Barnes, Ch., Bernstein, I. L., Bernstein, J. A., Nel, A., Peden, D., Diaz-Sanchez, D., Tarlo, S. M., \& Williams, P. B. (2004). Health effects of air pollution. Journal of Allergy and Clinical Immunology, 114(5), 1116-1123. https://doi.org/10.1016/j.jaci.2004.08.030

Domańska, D., \& Wojtylak, M. (2014). Explorative forecasting of air pollution. Atmospheric Environment, 92, 19-30. https://doi.org/10.1016/j.atmosenv.2014.03.041

European Commitee for Standartization. (2014). Ventilation for buildings - Performance testing of components/products for residential ventilation - Part 8: Performance testing of un-ducted mechanical supply and exhaust ventilation units (Including Heat Recovery) for mechanical Ve. n.d. (EN 13141-8:2014-09).

Griffiths, M., \& Eftekhari, M. (2008). Control of $\mathrm{CO}_{2}$ in a naturally ventilated classroom. Energy and Buildings, 40(4), 556-560. https://doi.org/10.1016/j.enbuild.2007.04.013

Grzebielec, A., \& Rusowicz, A. (2013). Analysis of the use of adsorption processes in trigeneration systems. Archives of Thermodynamics, 34(4), 35-49. https://doi.org/10.2478/aoter-2013-0028

Grzebielec, A., Rusowicz, A., Jaworski, M., \& Laskowski, R. (2015). Possibility of using adsorption refrigeration unit in district heating network. Archives of Thermodynamics, 36(3), 15-24. https://doi.org/10.1515/aoter-2015-0019

Grzebielec, A., Rusowicz, A., \& Ruciński, A. (2014). Analysis of the performance of the rotary heat exchanger in the real ventilation systems. In $9^{\text {th }}$ International Conference Environmental Engineering $\left(9^{\text {th }}\right.$ ICEE) - Selected Papers. Vilnius Gediminas Technical University Press. https://doi.org/10.3846/enviro.2014.259

Jaworski, M. (2019). Mathematical model of heat transfer in PCM incorporated fabrics subjected to different thermal loads. Applied Thermal Engineering, 150(5), 506-511. https://doi.org/10.1016/j.applthermaleng.2019.01.019

Kajurek, J., Rusowicz, A., Grzebielec, A., Bujalski, W., Futyma, K., \& Rudowicz, Z. (2019). Selection of refrigerants for a modified organic rankine cycle. Energy, 168, 1-8. https://doi.org/10.1016/j.energy.2018.11.024

KG, ebm-papst Mulfingen GmbH \& Co. (2012). EC centrifugal module-RadiCal.

Liu, C., Hsu, P. C., Lee, H. W., Ye, M., Zheng, G., Liu, N., Li, W., \& Cui, Y. (2015). Transparent air filter for high-efficiency $\mathrm{PM}_{2.5}$ capture. Nature Communications, 6, 6205. https://doi.org/10.1038/ncomms7205

Lund, H., Möller, B., Mathiesen, B. V., \& Dyrelund, A. (2010). The role of district heating in future renewable energy systems. Energy, 35(3), 1381-1390. https://doi.org/10.1016/j.energy.2009.11.023

Namieśnik, J., Górecki, T., Kozdroń-Zabiegała, B., \& Łukasiak, J. (1992). Indoor Air Quality (IAQ), pollutants, their sources and concentration levels. Building and Environment, 27(3), 339-356. https://doi.org/10.1016/0360-1323(92)90034-M

Owczarek, M., \& Baryłka, A. (2019). Determining the thermal diffusivity of the material based on the measurement of the temperature profile in the wall. Rynek Energii, 143(4), 63-69.

Park, J. H., Yoon, K. Y., \& Hwang, J. (2011). Removal of submicron particles using a carbon fiber ionizer-assisted medium air filter in a Heating, Ventilation, and Air-Conditioning (HVAC) System. Building and Environment, 46(8), 1699-1708. https://doi.org/10.1016/j.buildenv.2011.02.010

Pui, D. Y. H., Chen, S.-C., \& Zuo, Z. (2014). PM2.5 in China: Measurements, sources, visibility and health effects, and mitigation. Particuology, 13, 1-26. https://doi.org/10.1016/j.partic.2013.11.001

Rosbach, J. T., Vonk, M., Duijm, F., Van Ginkel, J. T., Gehring, U., \& Brunekreef, B. (2013). A ventilation intervention study in classrooms to improve indoor air quality: The FRESH study. Environmental Health: A Global Access Science Source, 12, 110. https://doi.org/10.1186/1476-069X-12-110

Rusowicz, A., \& Ruciński, A. (2011). The mathematical modelling of the absorption refrigeration machines used in energy systems. Environmental Energymental Energy, 802-806.

Rusowicz, A., Laskowski, R., \& Grzebielec, A. (2017). The numerical and experimental study of two passes power plant condenser. Thermal Science, 21(1), 353-362. https://doi.org/10.2298/TSCI150917011R

Wasilczuk, J. (2019). Threats occurring in the functioning of shelter ventilation installations. Modern Engineering, 2, 55-60.

Werner, S. (2017). International review of district heating and cooling. Energy, 137, 617-631. https://doi.org/10.1016/j.energy.2017.04.045

Xuehuan, Gao, Xu Yanyi, Cai Yunfei, Shi Jingjin, Chen Feier, Lin Zhijing, Chen Tianyi, Xia Yongjie, Shi Wenming, \& Zha Zhuohui. (2019). Effects of Filtered fresh air ventilation on classroom indoor air and biomarkers in saliva and nasal samples: A randomized crossover intervention study in preschool children. Environmental Research, 179(Part A), 108749. https://doi.org/10.1016/j.envres.2019.108749 